International Journal of Rotating Machinery 1999, Vol. 5, No. 1, pp. 35-40

Reprints available directly from the publisher

Photocopying permitted by license only
(C) 1999 OPA (Overseas Publishers Association) N.V.

Published by license under the Gordon and Breach Science Publishers imprint Printed in Malaysia.

\title{
Integrated Diagnostics and Prognostics of Rotating Machinery
}

\author{
KAM W. $\mathrm{NG}^{*}$ \\ Program officer, Office of Naval Research, ONR333, Mechanics \& Energy Conversion Division, \\ 800 North Quincy Street, Arlington, VA 22217-5600, USA
}

(Received 9 April 1998; In final form 10 May 1998)

\begin{abstract}
This paper provides an overview of current research efforts in integrated diagnostics and prognostics of rotating machinery. Specifically, the following topics are discussed: sensing techniques and sensors; signal detection, identification and extraction; classification of faults; predictive failure models; data/model fusion; information management; and manmachine interface. Technical issues, recommendations, and future research directions are also addressed.
\end{abstract}

Keywords: Condition-based maintenance, Diagnostics, Prognostics, Sensor, Detection and classification, Data fusion

\section{INTRODUCTION}

In product manufacturing and power generation operations, downtime and the associated costs of machinery breakdown can be significant and, at times, even crucial to continued viability. For military platforms and systems, failure of machinery can significantly reduce mission effectiveness, and could indirectly result in casualty and loss of national assets. As equipment ages, maintenance costs increase while reliability and safety margins decrease. Aging equipment, reduced personnel support, and a continuing emphasis on reduced operating budgets have combined to kindle great interest in machinery fault diagnosis and prognosis. The attention given to machinery diagnostics and prognostics is reflected in the large number of references in the literature, see Lyons (1987), Dimentberg et al. (1991), Cempel (1991), Natke and Cempel (1996), and the Proceedings from the MFPT meetings (1968-1997).

Rotating machinery is a major and critical component of many mechanical systems found in industrial plants, as well as in air and ground transportation vehicles and many other applications. The machinery's rotating elements have unique characteristics - both in performance and acoustics - that can be predicted. For example,

*Tel.: (703) 696-0812. Fax: (703) 696-2558. E-mail: ngk (a)onr.navy.mil. 
these rotating elements exhibit high harmonic oscillations when on the verge of failure. Thus, rotating machinery is an application where fault diagnosis is commonly employed as a maintenance methodology. This paper focuses on the maintenance diagnostics and prognostics of rotating machinery.

Recently, maintenance methodology has been shified toward Condition-Based Maintenance (CBM). CBM employs a continuous maintenance methodology to maximize availability of equipment. It is accomplished by continuously monitoring equipment conditions and performing maintenance actions only when faults exist. At the operational level, CBM alerts operators to evolving faults and allows maintenance actions to be taken before catastrophic failure occurs.

A schematic of a typical CBM system is shown in Fig. 1. The key components consist of machinery, sensors, fault detectors, fault classifiers, predictive models, model/data fusion, and outputs. In the following sections, technical issues and the functions of each component and their interfaces, as well as on-going research efforts, are discussed.

\section{Technical Issues}

Some of the issues relating to machinery diagnostics and prognostics are: (1) database, (2) real-time and on-line monitoring capabilities, (3) extraction of features from noisy environments, (4) errors and uncertainties in detection and classification leading to false alarm, and (5) identification of the dominant modes of failure.

A comprehensive database of machinery monitoring signals covering normal operation to failure is lacking, principally because legal issues restrict the dissemination of machinery failure data. To circumvent this difficulty, artificial or simulated (seeded) faults are introduced to speed up the machinery degradation process.

From a fault detection and classification viewpoint, it is ideal to have real-time and on-line capabilities. However, it is an on-going challenge to develop such data acquisition and signal analyses systems. To deal with background noise contamination and interference, signal enhancement or noise removal techniques are applied to monitored signals. Errors and uncertainties in detection and classification of fault features can lead to false alarms. This issue becomes the motivation for developing a robust and reliable machinery monitoring system.

In failure analysis, identification of the failure mode is one of the key objectives. It is also the first step to an understanding of how a mechanical component fails. This understanding can then be used to develop a physics-based model.

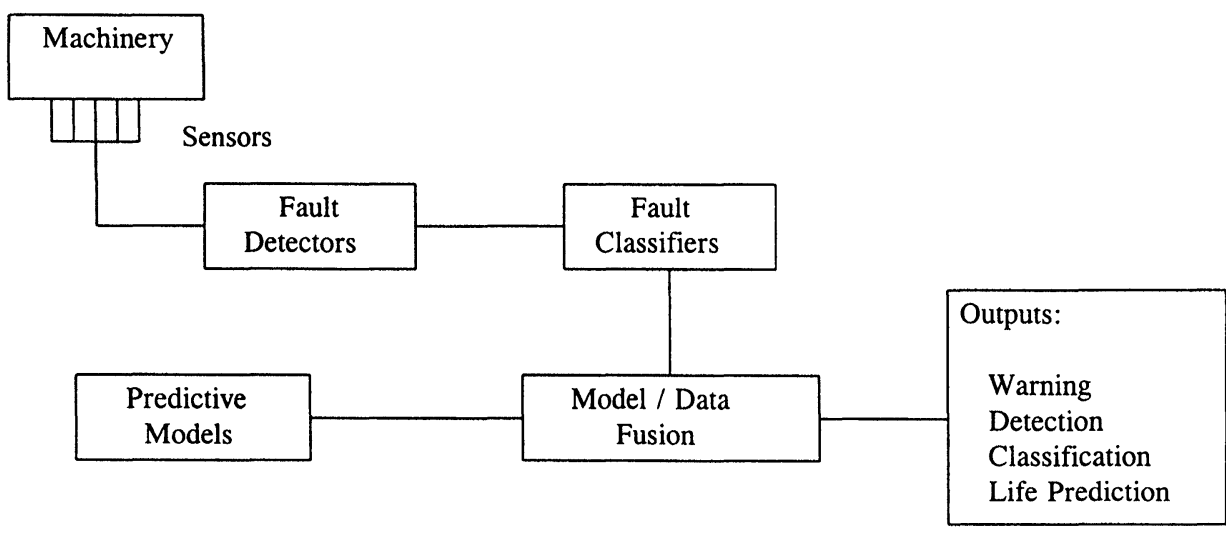

FIGURE 1 Key elements of condition-based maintenance system. 


\section{SENSING TECHNIQUES AND SENSORS}

\section{Monitoring Parameters}

The monitoring of machinery performance and its operating condition can be accomplished through careful selection of measured parameters. The most common parameters are vibration and acoustic signatures, temperature, pressure, motor current, wear debris and electrostatic exhaust measurements. To detect failure inception, deterioration mechanisms are continuously monitored and initiation of cracks, fractures, and other failures, such as shaft cracks, seal leakage, and corrosions are identified.

\section{Sensing Techniques}

Sensing techniques have undergone continuous development. State-of-the-art techniques include: active interrogation approaches, nondestructive evaluations such as acoustic emission and stress wave monitoring, holographic imaging, oil debris analysis, chemical composition and analysis, use of in situ and embedded microsensors, electrostatic exhaust measurements, remote sensing, and electrical resistance measurements. Also important are the optimal placement of sensors and a sensing strategy that monitors small changes in state variables that could capture fault precursors and features. Virtual sensor concept, a simulation and modeling of signals based on limited data and measurements, has good potential to reduce the number of sensors and thus cost.

\section{Sensors}

Recent advances in materials and sensor development, combined with new manufacturing techniques (e.g., nanofabrication) have allowed manufacturers to build rugged sensors that are affordable and miniature in size. The new materials and processing include piezoelectric elements, piezofilm, piezocomposites, optical fibers, and micro-electromechanical systems (MEMS). In addition, biosensors are being developed to sense and identify chemical species, which will have good potential for use in fault diagnostics.

\section{FEATURE EXTRACTION}

\section{Detection and Identification}

With the increasing need for identification and location of incipient failures, new signal processing techniques have been implemented to enhance detection and identification of fault precursors and features. Specifically, signal enhancement or background noise removal, and signal detection techniques are used. The signal processing techniques include cepstral analysis, time-frequency analysis, nonlinear dynamic techniques, and higher and lower order spectral analyses. Time-frequency analyses such as the Wigner distribution and wavelet transforms have been used and successfully demonstrated to detect and identify fault features. Sources of higher harmonic oscillations in rotating machinery have been found to be caused by imbalance, misalignment, and nonlinear excitation. It has been observed that nonlinear dynamic techniques and lower and higher order spectral (polyspectral) analyses techniques can be used to detect and identify higher harmonic oscillations, as well as fault features. In particular, alpha-stable distributions, a lower-order statistics method, has been developed to detect impulsive type features embedded in non-Gaussian signal.

\section{Feature Classification}

Once fault features are detected, identified and extracted using signal processing techniques, the fault features are transformed to fault vector space where classification is performed. Classification techniques include conventional statistical methods, neural networks, fuzzy logic, and pattern recognition. Neural networks have been commonly applied to fault vectors to train and classify the various faults. Fuzzy logic, a rule-based reasoning approach, has been used successfully to classify faults. Efforts are on-going to combine neural networks and fuzzy logic, the so-called neuro-fuzzy 
network approach, to classify fault precursors and features. Pattern recognition still remains as one of the classification techniques for faults.

\section{PREDICTIVE MODEL}

Failure analysis, which plays an important role in understanding how components fail, forms the basis of the failure predictive models. As mentioned previously, failure mode identification and classification is one of the technical issues. Though failure mechanisms have been studied for a long time, understanding how failures occur and theoretical development in predicting mechanical failures are far from satisfactory. In particular, there is a need for physics-based models relating fundamentals with experimental data to predict the remaining useful (safe operating) life of structures and components. The challenge is to model fault initiation and propagation as a unified approach and then predict state variables that relates to mechanical response or vibration. A statistical approach has been used to predict the fatigue life expectancy of structural components subject to cyclic loading. This approach deals with the statistical variability in such quantities as material properties and initial flaw sizes, as well as the statistical nature of the fatigue process.

\section{DATA/MODEL FUSION}

Data monitoring and predictive models need to be fused to enhance decision-making and to provide reliable information and warning to operators. Occasionally, signals from multiple sensor inputs and models can be contradictory; therefore, selection of the proper data and integration or fusion of this information are critical in the reasoning and decision-making processes.

\section{INFORMATION MANAGEMENT AND MAN-MACHINE INTERFACE}

The purpose of any diagnostic and prognostic system is to provide early failure warning to the operators. More important, such a system predicts useful life after a fault precursor is detected. In addition to providing reliable information to the operators, the outputs from the diagnostic and prognostic system must be simple enough that the operators can understand them and thus take appropriate corrective actions.

An information system workstation is required to integrate data monitoring, predictive models, and decision support systems for maintenance operators in carrying out troubleshooting, manmachine interface, and operator training.

\section{CURRENT RESEARCH ACTIVITIES}

In view of the requirements and opportunities in science and technology, both government and industry have engaged in a wide spectrum of research and development efforts in CBM. For example, the Office of Naval Research (ONR) has embarked on an integrated science and technology program in CBM. A listing of current research activities in CBM is summarized below. As shown, the research and development efforts cover a wide range of projects in basic and applied research, as well as advanced engineering development in the areas of sensing techniques and sensors, fault detection and classification, predictive models and information management, and maintenance system development.

\section{Current CBM Activities at ONR}

(1) Multidisciplinary University Research Initiative (Basic Research)

(a) Penn State University/Rensselaer Polytechnic Institute

- Sensor, Fault Detection \& Classification, Active Methodology, Data Fusion

(b) Georgia Institute of Tech./Northwestern/ University of Minnesota

- Microsensor, Fault Detection \& Classification, Failure Mechanisms \& Life Estimation 
(2) Future Navy Capabilities Option (Basic \& Applied Research \& Advanced Development)
(a) Machinery
- Penn State University: Gas Turbine Generator
- Honeywell Team: Centrifugal Compressor
(b) Oil Debris Analysis
- Naval Research Laboratory: LASERNET
(c) Corrosion
- Naval Air Warfare Center: Aircraft Corrosion
- Naval Surface Warfare Center: Valves
(d) Information Management and Training

(3) Surface Ship Technology (Applied Research) Naval Surface Warfare Center, Annapolis: Diagnostics of Electrical Components

(4) Logistics (Applied Research) Naval Surface Warfare Center, Annapolis: Diagnostics of Mechanical Components

(5) DARPA Flexible Fabrication Program University of Arkansas: Portable holographic technique for monitoring stress and strain in structures

(6) DARPA Technology Reinvestment Program Model Based Control Diagnostics: GE Aircraft Engine, GE R\&D, Lockheed Martin, Ford: Aircraft Engines and Automobile Engines

(7) SBIR Phase II

Barron Associates: Prognostics of Gear

Specifically, two parallel and complementary research initiatives in CBM have been conducted by the Penn State University, and Georgia Institute of Technology teams. A Future Naval Capabilities Option is underway by the partnership of universities and industry in the focus areas of machinery, oil debris analysis, corrosion of piping and valves, and information management and training. In particular, the maintenance of gas turbine generator is addressed by the Penn State University team, and the centrifugal compressor problem is being considered by the Honeywell team. Diag- nostics of rotating machinery and electrical components is being investigated at the Naval Surface Warfare Center (NSWC) in Annapolis, Maryland. In the Flexible Fabrication Program under sponsorship of the Defense Advanced Research Agency (DARPA), the University of Arkansas is developing a portable holographic technique for monitoring stress and strain in structures. In the DARPA's Technology Reinvestment Program, the GE Aircraft Engine Consortium is developing model-based control diagnostic systems for aircraft engines and automobile engines. Under a Small Business Innovative Research (SBIR) Phase II effort, Barron Associates is developing prognostic capability for the gear component.

\section{CONCLUSIONS}

Integrated diagnostics and prognostics is an emerging technology in performing effective rotating machinery maintenance. In the last decade, progress has been made in machinery diagnostics, which includes sensing techniques, sensor development, and advanced signal processing techniques. There is a need to speed up the signal processing and analyses to provide real-time and on-line capability. Wireless communication and remote sensing techniques show some promise and should be considered for implementation. Machinery prognostics is a very challenging task, and its progress has not kept up with that of diagnostics. Accordingly, a better understanding of failure mechanisms, together with development of physics-based models, is needed to achieve the prognostics capability.

Though the CBM approach is effective, the cost of sensor arrays, related instrumentation and hardware, and the information system could be significant. To meet the objective of reducing overall maintenance costs, innovative concepts and techniques are required to develop, design and fabricate cost-effective sensors, signal processing 
algorithms, and information system software and related hardware. For example, virtual sensor concept, and combined sensor and signal processing electronic chip could reduce cost and provide improved system integration.

In addition to providing reliable information to maintenance operators, the outputs of the CBM system have to be simple enough for the operators to understand and thus take timely corrective actions. Accordingly, improvements are needed in man-machine interface and display of outputs.

\section{References}

Cempel, C., 1991, Vibroacoustic Condition Monitoring, Ellis Horwood.

Dimentberg, M.F., Frolov, K.V. and Menyailov, A.I., 1991, Vibroacoustical Diagnostics for Machines and Structures, Research Studies Press Ltd.

Lyons, R.H., 1987, Machinery Noise and Diagnostics, Butterworth-Heinemann.

Natke, H.G. and Cempel, C., 1996, Model-Aided Diagnosis of Mechanical Systems - Fundamentals, Detection, Localization, and Assessment, Springer-Verlag.

Proceedings of the Society for Machinery Failure Prevention Technology (MFPT, formerly MFPG), 1968-1997, Vibration Institute. 


\section{ait \\ ENERGY MATERIALS}

M A N E Y publishing

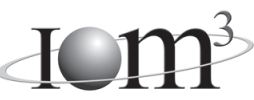

\section{Materials Science \& Engineering for Energy Systems}

Maney Publishing on behalf of the Institute of Materials, Minerals and Mining

The Institute of Materials, Minerals \& Mining

Economic and environmental factors are creating ever greater pressures for the efficient generation, transmission and use of energy. Materials developments are crucial to progress in all these areas: to innovation in design; to extending lifetime and maintenance intervals; and to successful operation in more demanding environments. Drawing together the broad community with interests in these areas, Energy Materials addresses materials needs in future energy generation, transmission, utilisation, conservation and storage. The journal covers thermal generation and gas turbines; renewable power (wind, wave, tidal, hydro, solar and geothermal); fuel cells (low and high temperature); materials issues relevant to biomass and biotechnology; nuclear power generation (fission and fusion); hydrogen generation and storage in the context of the 'hydrogen economy'; and the transmission and storage of the energy produced.

As well as publishing high-quality peer-reviewed research, Energy Materials promotes discussion of issues common to all sectors, through commissioned reviews and commentaries. The journal includes coverage of energy economics and policy, and broader social issues, since the political and legislative context influence research and investment decisions.

\section{CALL FOR PAPERS}

Contributions to the journal should be submitted online at http://ema.edmgr.com

To view the Notes for Contributors please visit: www.maney.co.uk/journals/notes/ema

Upon publication in 2006, this journal will be available via the Ingenta Connect journals service. To view free sample content online visit: www.ingentaconnect.com/content/maney

For further information please contact:

Maney Publishing UK

Tel: +44 (0)113 2497481 Fax: +44 (0)1132486983 Email: subscriptions@maney.co.uk

or

Maney Publishing North America

Tel (toll free): 8662975154 Fax: 6173546875 Email: maney@maneyusa.com

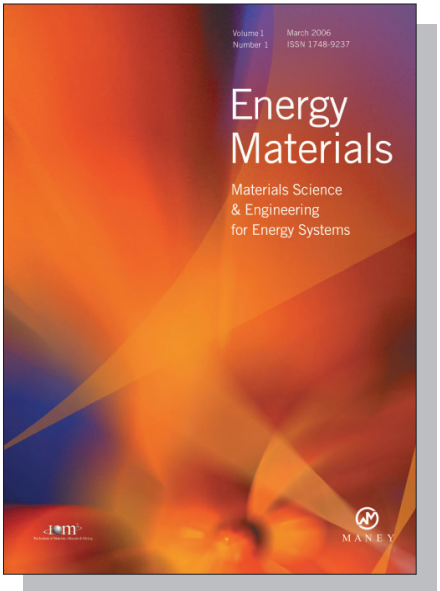

EDITORS

Dr Fujio Abe

NIMS, Japan

Dr John Hald, IPL-MPT, Technical University of Denmark, Denmark

Dr R Viswanathan, EPRI, USA

\section{SUBSCRIPTION INFORMATION}

Volume 1 (2006), 4 issues per year

Print ISSN: 1748-9237 Online ISSN: 1748-9245

Individual rate: $£ 76.00 / U S \$ 141.00$

Institutional rate: $£ 235.00 /$ US $\$ 435.00$

Online-only institutional rate: $£ 199.00 / U S \$ 367.00$

For special $\mathrm{IOM}^{3}$ member rates please email

subscriptions@maney.co.uk

\section{For further information or to subscribe online please visit www.maney.co.uk}



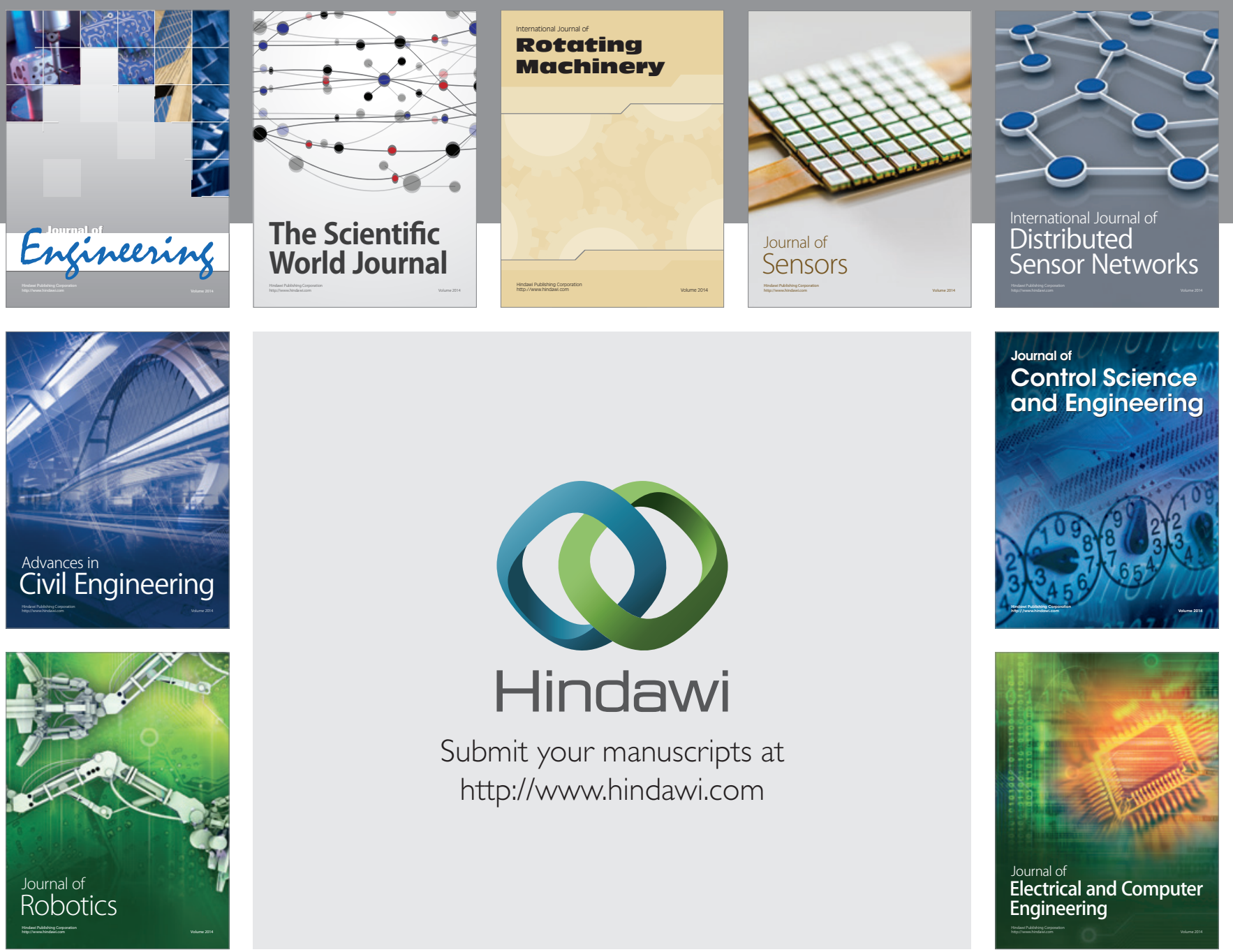

Submit your manuscripts at

http://www.hindawi.com
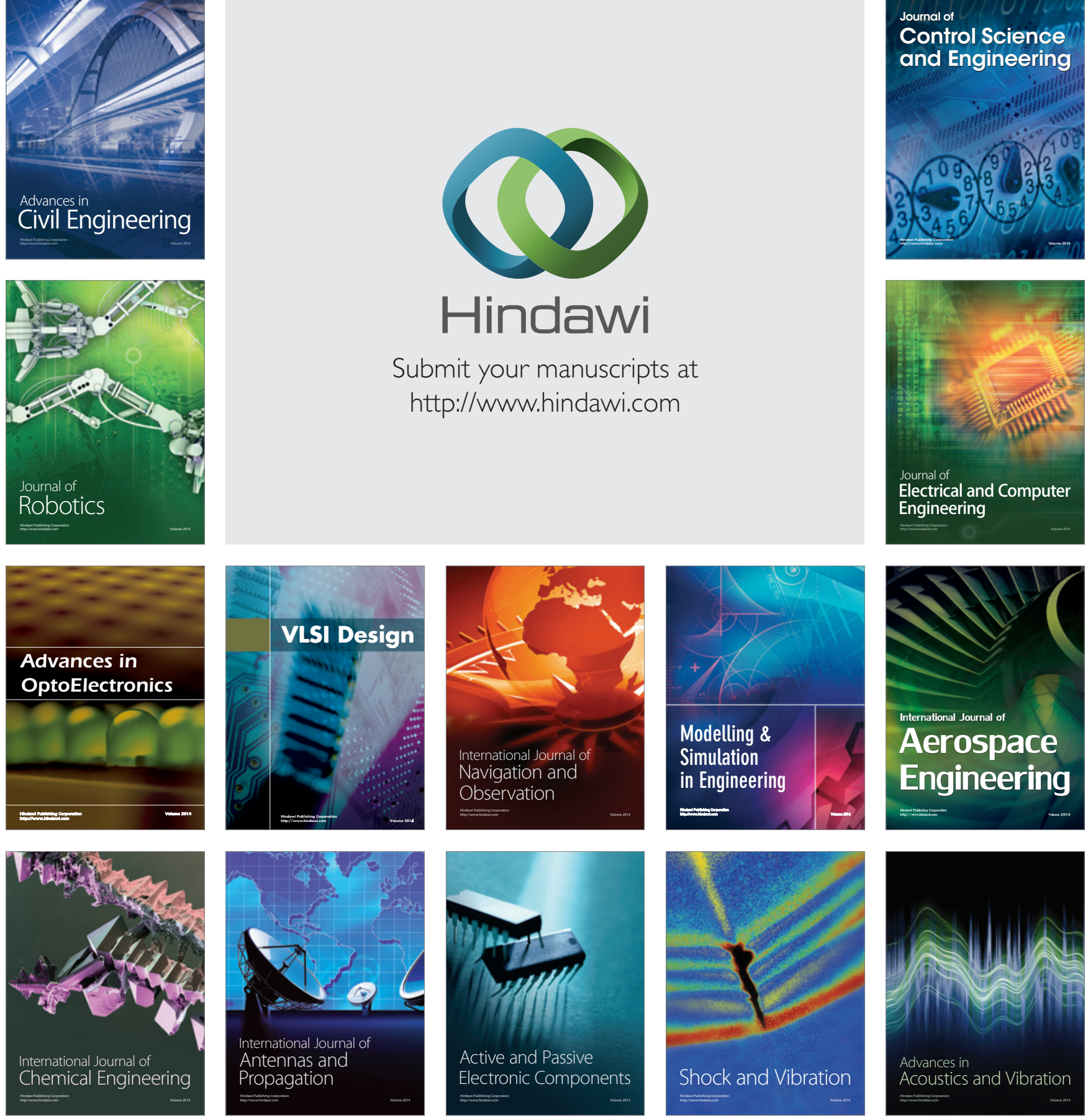